\title{
CONTEXTUAL AND PROCEDURAL DETERMINANTS OF PARTNER SELECTION: OF ASYMMETRIC DOMINANCE AND PROMINENCE
}

\author{
CONSTANTINE SEDIKIDES \\ University of Southampton England, UK \\ DAN ARIELY \\ Massachussetts Institute of Technology and Sloan Schoolof Business \\ NILS OLSEN \\ University of North Carolina at Chapel Hill
}

\begin{abstract}
The early stage of partner selection is conceptualized as a decision-making process amenable to at least two types of influence: contextual and procedural. An example of contextual influence is the asymmetric dominance effect. According to this effect, introduction in a twoperson field of eligibles of a third eligible, who is domnated (i.e., is inferior) on an attribute by the first eligible but not by the second one, will tip the scale toward selecting the first eligible. An example of procedural influence is the prominence effect. According to this effect, participants will be more likely to select in choice rather than in matching the eligible who is superior on an attribute important to the participants. On the other hand, participants will be more likely to select in matching rather than in choice the eligible who is superior on an attribute unimportant to the participants. Two experiments demonstrated these contextual and procedural influences.
\end{abstract}

This article is concerned with antecedents of dating partner selection. Why do individuals select as an eligible dating partner Person A instead

A portion of this research was presented a the 1997 North Carolina Cognition Group meeting, Chapel Hill, North Carolina, February. The authors are grateful to Geraldine Downey, Harry Reis, Harry Upshaw, and three anonymous reviewers for their constructive comments on earlier drafts of this article, to Klaus Fiedler, Manfred Hassebrauck and Denis Hilton for stimulating conversations, and to Greg Auman, Nina Jones, and especially Patricia Linville for their contribution to various stages of this research. Last but not least, the authors thank their partners to whom their love and devotion does not depend on contextual or procedural influences.

Address correspondence to Constantine Sedikides, Department of Psychology, University of Southampton, Highfield Campus, S017 1BJ, England, UK; E-mail: diony sus@unc.edu. 
of B or C? More specifically, is selection of Person A over Person B affected by the presence or absence of a seemingly irrelevant alternative, namely Person C? Furthermore, does the nature of the selection process affect the selection outcome? We will provide a thumbnail description of social psychological theorizing on the issue of partner selection. Subsequently, we will complement the extant literature with a view based on decision theory. Finally, we will report two experiments that illustrate and document our view.

\section{SOCIAL PSYCHOLOGICAL THEORIZING ON PARTNER SELECTION: A BRIEF EXPOSITION AND AN ATEMPT TO EXPAND ITS EXPLANATORY SCORE}

The problem of partner selection has attracted an abundance of theoretical and empirical attention in social psychology. Interdependence theory (Kelley \& Thibaut, 1978; Thibaut \& Kelley, 1959) posits the operation of two mechanisms in the partner selection process: comparison level (CL) and comparison level for alternatives (CL-alt). CL describes the individual's expectancies about a prospective relationship. These expectancies are based on past relationships and social comparison processes. CL-alt refers to the individual's lowest bounds of acceptable relationship outcomes, given outcomes obtainable in other relationships. The CL-alt is set partly by the desirability of alternatives. Attachment theory (Hazan \& Shaver, 1994) postulates three types of attachment styles: secure, anxious/ambivalent, and anxious/avoidant. Research has shown that individuals prefer partners with an attachment style similar to theirs (Frazier et al., 1996; Pietromonaco \& Carnelley, 1994), although recent evidence points to a general preference for securely attached partners (Chappell \& Davis, 1998). From a need-based perspective, partner selection satisfies psycho-logical needs, such as the need to belong (Baumeister \& Leary, 1995), the need for intimacy (Reis \& Shaver, 1988), the need for positive affect maintenance (Sedikides, Oliver, \& Campbell, 1994), or the need to expand the self (A. Aron \& E. Aron, 1997). From an evolutionary psychology perspective (Buss, 1989; Sadalla, Kenrick, \& Vershure, 1987), partner se-lection follows a gender-specific pattern: Women prefer men who rank highly on social status, material resources, and dominance, whereas men prefer physically attractive women. From a broad, behavioristic standpoint, individuals are attracted to partners whose presence is re-warding (Lott \& Lott, 1974). Research has also highlighted the role of as-sorted variables in partner selection, such as similarity of personality (Tharp, 1963), attitudes (Byrne, 1971), demographic characteristics (Newcomb, 1961) or physical features (Hinsz, 1989), similarity of the 
partner to one's ideal self (Wetzel \& Insko,1982), proximity (Newcomb, , the belief that the prospective partner finds one appealing (A. , Dutton, E. Aron, \& Iverson, 1989), and physiological arousal on \& A. Aron, 1974). The abovementioned theoretical statements moved the field of personal relationships substantially forward. present research focuses on a somewhat different partner selecetting. The research (i.e., Experiment 1) is designed to provide an Lnt for the initial selection of a specific romantic (i.e., dating) partner mother eligible (1) as a function of the presence or absence of addil eligibles, and (2) when variables pertinent to the selection process CL, needs, similarity) are held constant. ${ }^{1}$ Consider the case of Lori, las just met Antawn and Serge. We are not interested in why Lori t select Antawan as her dating partner over Serge; rather, we are in-ed in why Lori might select Antawan over Serge as a function of eeting versus not meeting Trajan, a third and rather weak eligible. d Lori's selection of Antawn over Serge (two eligibles who are prebly securely attached, equally high on social status, and express at-!s that are equally similar to hers) be amenable to a contextual once, namely sensitivity to a seemingly undesirable alternative, is Trajan?

litionally, our research (i.e., Experiment 2) purports to account for Tact on the selection outcome of the specific form or procedure le selection process takes. Two forms that the selection process can is a choice question (i.e., "Do I choose Antawn or Serge as a dating n?") or a matching question (i.e., "How much would Serge need to 1ve on a given attribute in order for me to find him as appealing as vn?"). Will Lori's dating selection outcome depend on the procei.e., choice vs. matching question) that guides her search?

$\mathrm{s}$, we intend to expand the explanatory scope of prior research by wledging particular forms of contextual and procedural influence -trier selection. We believe that our understanding of the partner on process will increase by challenging two implicitly held as-ions: that partner selection is relatively unaffected (1) by the con-tion of the social context in which the partner is embedded :tual invariance assumption) and (2) by the procedure that is used to the partner (procedural invariance assumption).

assume that the early stage of partner selection is a decilaking process that takes place frequently under conditions of unity and time pressure. Initial partner selection is an on-line and ve search that involves the use of judgmental heuristics. As such,

1. We assume that relatively little information about th4 eligibles is available at selection time. 
partner selection is amenable to at least two types of influence: contextual and procedural.

\section{CONTEXTUAL DETERMINANTS OF PARTNER SELECTION: ASYMMETRIC DOMINANCE}

Contextual influences describe factors associated with the specific values of the objects in the set that the decision maker considers (Payne, Bettman, \& Johnson, 1993). In the present research, values refer to the level of personality attributes, objects refer to specific dating eligibles, and set refers to the field of eligibles. A contextual effect of present in terest is the asymmetric dominance effect (Huber, Payne, \& Puto, 1982; Huber \& Puto, 1983). The asymmetric dominance effect is an empirical generalization that refers to the phenomenon in which the salience and desirability of one alternative (e.g., dating eligible) over another changes as a function of the introduction of a third alternative. This phenomenon holds under the supposition that the newly introduced alternative is inferior to (i.e., is dominated by) the first alternative but not the second one.

Let us revisit our fictional characters. Lori has just met Antawn and Serge. Antawn is very handsome (e.g., falls on the 90th percentile on handsomeness) but is rather inarticulate (40th percentile), whereas Serge is not really handsome (40th percentile) but is very articulate (90th percentile). Lori is perplexed because of the conflicting personality at-tributes of the two men, and realizes that trade-offs will be required. Thankfully and conveniently, Trajan enters the picture. Trajan is fairly handsome (80th percentile) but is also rather inarticulate (40th percentile). Introduction of Trajan into the field of eligibles now solidifies Lori's decision. She will likely select Antawn.

In the above illustration of a hypothetical occurrence of the asymmetric dominance effect, Lori was faced with two alternatives: Antawn and Serge. Antawn was superior to Serge on handsomeness but inferior on articulation. (See left panel of Figure 1.) Then, a third alternative came along, Trajan. This third alternative was similar to Antawn on handsomeness but inferior on articulation. (See right panel of Figure 1.) Trajan was dominated by Antawn but not by Serge; that is, Trajan was dominated asymmetrically. Trajan, the asymmetrically dominated alternative, would not likely be selected because he was clearly inferior to one of the alternatives (i.e., Antawn). However, the addition of this asymmetrically dominated alternative into the field of eligibles increased the selection of the alternative that dominated it. Stated otherwise, Trajan helped rather than hurt Lori's selection of 

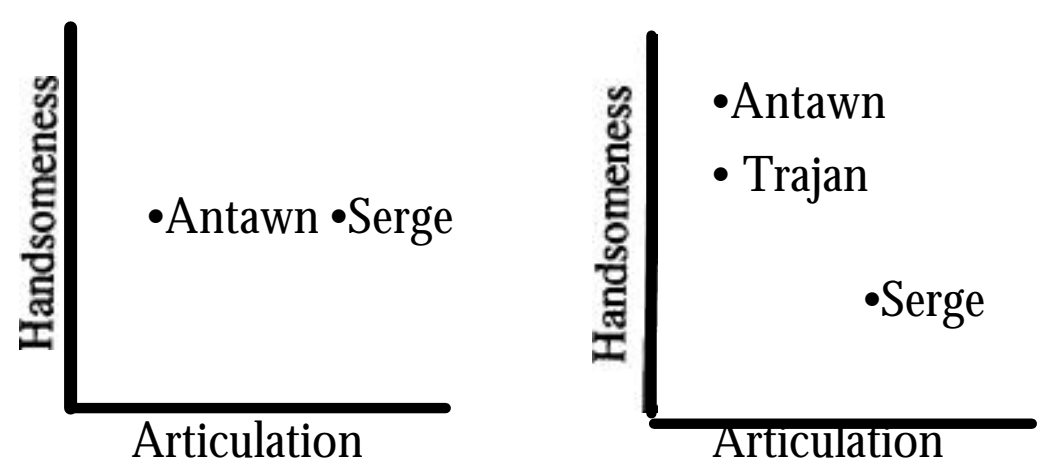

FIGURE 1. An illustration of the asymmetric

\section{PROCEDURAL DETERMINANTS OF PARTNER SELECTION: PROMINENCE}

Procedural influences refer to factors associated with structural characteristics (i.e., solution method or approach tactic) of the problem (e.g., partner selection) that the decision maker considers (Payne et al., 1993). Does thinking about a problem in different terms produce different results? More relevant to the present investigation, does expressing partner selection preferences in different ways lead to different partner selection outcomes? A procedural effect with which we are concerned is the prominence effect.

Individuals can express preferences in terms of at least two general modes: choice or matching. In choice, the individual selects an alternative from a set of two or more alternatives. In matching, the individual sets the value of an alternative to a level that would make this alternative as appealing as another alternative in the set. When Lori selects Antawn over Serge on the basis of handsomeness, she uses a choice response task. On the other hand, when Lori states that Serge would need to be on the 75th percentile on handsomeness in order for her to find him as appealing as Antawn, she uses a matching response task.

The matching response task can be viewed as a measure of implied choice. Consider Panel I in Table 1. Two hypothetical eligibles (A and B) are described with regard to two positive attributes (1 and 2). Now consider Panel II. What level of Attribute 1 should B possess in order to be as appealing as A? If this level exceeds the corresponding level of A (i.e., > 
Table 1. An illustrationof the Matching Response Task as Implied Choice

\begin{tabular}{|l|l|l|}
\hline PANEL 1 & Eligible A & \\
\hline & 40 & Eligible B \\
\hline Attribute 1 & 80 & 80 \\
\hline Attribute 2 & & 40 \\
\hline PANEL II & Eligible A & \\
\hline & 40 & Eligible B \\
\hline & 80 & {$[?]$} \\
\hline & Person A & 40 \\
\hline PANEL III: Implied Participant Choice of A over B & \\
\hline \multicolumn{2}{|l|}{40} & Person B \\
\hline & 80 & {$[>80]$} \\
\hline & 40 \\
\hline PANEL IV Implied Participant Choice of B over A & \\
\hline \multicolumn{2}{|l|}{ Person A } & Person B \\
\hline Attribute 1 & 40 & {$[<80$} \\
\hline Attribute 2 & 80 & 40 \\
\hline PANEL V: Implied Participant Preference of A over B & \\
\hline & Person A & Person B \\
\hline Attribute 1 & 40 & {$[80]$} \\
\hline Attribute 2 & 80 & 40 \\
\hline & & \\
\hline
\end{tabular}

Note. Both attributes are considered positive.

80), as in Panel III, then the experimenter can infer that the participant prefers A over B. On the other hand, if this level is lower than the corresponding level of A (i.e., < 80), then the experiment infers that the participant prefers B over A (Panel IV). Finally, if this level is equal to A's (i.e., 80), this would imply an equal preference for $A$ and $B$ (Panel V). In summary, the level of the attribute that participants declare in reference to $B$ in the matching response task is taken as the participants' indirect (i.e., implied) choice with regard to A; this level is subsequently compared with the participant's selection pattern of $\mathrm{A}$ in the choice response task.

Logically, choice and matching should produce the same decision out-come. This is indeed the case when one eligible has an overwhelmingly undesirable attribute (e.g., Serge has bad breath) and when preferences are defined a priori, unequivocally and with a high degree of confidence (e.g., Lori is absolutely certain that the best eligible for her is the man with the hairiest chest). We assume, though, that early preferences are developed in an on-line and tentative manner. Hence, they can be re-versed as a function of a choice versus a matching response task.

Imagine that Lori still regards Antawn as more handsome, albeit less articulate, than Serge. Now, let us assume that Lori considers hand- 
someness a more important attribute than articulation in a dating partner. The prediction is that Lori will manifest a stronger preference for Antawn when expressing her preference in terms of choice rather than matching. (Stated otherwise, Lori will select Antawn over Serge when expressing her preference in terms of choice.) Conversely, let us make a different assumption, namely that Lori considers handsomeness a less important attribute than articulation in a dating partner. In this case, the prediction is that Lori will manifest a weaker preference for Antawn when expressing her preference in terms of choice than matching. (Stated otherwise, Lori's matching response will imply that she selected Serge over Antawn.)

The above hypothetical illustration of preference reversal is known as the prominence effect (Slovic, 1975; Tversky, Sattath, \& Slovic, 1988). Participants will be more likely to select the eligible who is superior on the most important (or prominent) attribute in choice rather than in matching response tasks. Conversely, participants will be more likely to select the eligible who is superior on the least important attribute in matching than in choice response tasks. That is, participants will give more weight to important attributes when evaluating eligibles in a choice than a matching mode, and conversely they will give more weight to unimportant attributes when evaluating eligibles in a matching than a choice mode.

\section{EXPERIMENT 1: ASYMMETRIC DOMINANCE AND PARTNER SELECTION}

The objective of Experiment 1 was to demonstrate the relevancy of the asymmetric dominance effect to initial partner selection. We constructed three fields of eligibles: The first field consisted of eligible A (targeted alternative) and eligible B. The second field consisted of eligible A, eligible B, and eligible Ca (the decoy for A ). Ca was dominated by A but not by B. The third field of eligibles consisted of eligible $\mathrm{A}$, eligible $\mathrm{B}$, and eligible $\mathrm{Cb}$ (the decoy for $\mathrm{B}$ ). $\mathrm{Cb}$ was dominated by $\mathrm{B}$ but not by A. We presented the three fields of eligibles to participants on a betweenparticipants basis.

We derived three predictions regarding partner selection patterns. We will express these predictions in terms of the probability of participants selecting as a dating partner eligible $\mathrm{A}$ over eligible $\mathrm{B}$, as a function of eligibles $\mathrm{Ca}$ or $\mathrm{Cb}$.

Prediction 1: The probability of selecting A over $\mathrm{B}$ will be significantly higher when $\mathrm{Ca}$ is present in the field than when $\mathrm{Ca}$ is absent. That is, $\mathrm{P}(\mathrm{A}$ I BCa $)>\mathrm{P}(\mathrm{A}$ I B).

Prediction 2: The probability of selecting A over B will be significantly 
lower when $\mathrm{Cb}$ is present in the field than when $\mathrm{Cb}$ is absent. That is, $\mathrm{P}(\mathrm{A} \mathrm{I} \mathrm{BCb})<$ P(A I B).

Prediction 3 follows logically from predictions 1 and 2: The probability of selecting $\mathrm{A}$ over $\mathrm{B}$ will be significantly higher when $\mathrm{Ca}$ is present in the field than when $\mathrm{Cb}$ is present. That is, $\mathrm{P}(\mathrm{A}$ I BCa $)>\mathrm{P}(\mathrm{A}$ I BCb $)$.

\section{METHOD}

PARTICIPANTS AND EXPERIMENTAL DESIGN

A total of 120 students participated in this experiment. Participants were 90 University of North Carolina at Chapel Hill (UNC-CH) students and 30 Duke University (DU) students. The ratio of UNC-CH to DU students was the same across the levels of the between-participants factor. Most of the participants were single (88\%), Caucasian (65\%), females (70\%), and were not in a dating relationship (61\%). The average participant age was 21.65 years. UNC-CH students were approached at various places on campus (e.g., libraries, cafeteria) and were offered $\$ 3$ to complete a 10-15 minute survey regarding dating. The majority of these students (over 85\%) agreed to participate. DU participants were students in an undergraduate introductory marketing class and completed the survey in the classroom. We assigned participants randomly to the experimental conditions.

The experimental design, a balanced factorial, consisted of two factors: Field of Eligibles and Replication Set. Field of Eligibles, a between-participants factor, had three levels: $\mathrm{AB}$ (baseline), $\mathrm{ABCa}$ (decoy for eligible $\mathrm{A}$ present), and $\mathrm{ABCb}$ (decoy for eligible B present). Replica-tion Set had 10 levels (i.e., 10 stimulus sets). Each participant received a different random order of the stimulus sets.

Only the selection of eligible A over eligible B was at issue in the data analyses, regardless of whether participants were presented with these two alternatives alone or in combination with eligible $\mathrm{C}$. Given that the particular levels of $\mathrm{AB}$ combinations were the same for all participants, we considered the Replication Set (R) as crossed with Field of Eligibles (F), and participants (P) as nested in REP(F)]. Participants were a random variable and so was Replication Set. Consequently, the $\mathrm{RP}(\mathrm{F})$ variance was the error term for the $\mathrm{P}(\mathrm{F})$ effect, the RF effect, and the R effect; the cell variance became the error term for testing an $\mathrm{RP}(\mathrm{F})$ effect; finally, the F effect was tested against a term computed from the expected mean squares.

\section{STIMULUS MATERIALS}

In a pilot study ( $n=47 ; 29$ women, 17 men), we found that UNC-CH students consider the following five attributes (in descending order of importance) as most important in a person: physical attractiveness, 
honesty, sense of humor, dependability, and intelligence. Although these responses referred to a generalized other rather than a prospective dating partner, we nonetheless decided to use the attributes and their importance order in the present research.

We assigned the five attributes into all possible triplets under the constraint that attributes maintain their relative order of importance. For ex-ample, physical attractiveness (hereafter referred to as attractiveness) ought to precede honesty, and honesty ought to precede sense of humor. We applied this rule in order to maintain structural coherence within each stimulus set. This procedure resulted in 10 stimulus sets.

Next, we created the values of the attributes. We started with eligible A. For the first (i.e., the most important) attribute of each set, we chose a random value between 70 and 86 . For the second attribute, we chose a random value between 51 and 60. For the third attribute, we chose a random value between 54 and 69 . Attribute values assigned to eligible B were virtually a constant function of A's attribute values. That is, in relation to A, B's attribute values were approximately as follows: $75 \%$ for the first attribute, $109 \%$ for the second attribute, and $133 \%$ for the third attribute. Likewise, eligible Ca's attribute values were a constant function of A's attribute values (i.e., 100\%, 100\%, 83\%), and eligible Cb's attribute values were a constant function of B's attribute values (i.e., 100\%, 100\%, 87\%). Again, our objective in stimulus materials construction was the maintenance of a relatively homogenous internal structure across the stimulus sets. These stimulus sets are presented in Table 2.

\section{PROCEDURE}

All stimulus materials were included in the same booklet. The cover page of the booklet read as follows:

Often times, we are confronted with choices regarding dating partners. Which person (among several) should we choose to ask out for a date? When presented with several prospective dating partners, which partner do we choose to date? You will be presented with several hypothetical per-sons. Think of these persons as prospective dating partners. You will be asked to choose the one person you would ask out for a date. Please assume that all prospective dating partners are: (1) UNC (DU) students, (2) of the same ethnicity or race as you are, and (3) of approximately the same age as you are. The prospective dating partners will be described in terms of several attributes. A percentage point will accompany each attribute. This percentage point reflects the relative position of the prospective dating partner on that trait or characteristic, compared to UNC (DU) students who are of the same gender, race, and age as the prospective partner is. As an example, 
TABLE 2. Stimulus Materials for Experiment 1: Attribute Order Within Each Set, and Attribute Values (Expressed in Percentages) in Reference to Eligible A, Eligible B, the Decoy for A (Eligible Ca), and the Decoy for B (Eligible $\mathrm{Cb}$ )

\begin{tabular}{|c|c|c|c|c|c|}
\hline Set & Attribute & EligibleA & Eligible B & Eligible Ca & Eligible $\mathrm{Cb}$ \\
\hline \multirow{3}{*}{1} & Attractiveness & 80 & 60 & 80 & 60 \\
\hline & Honesty & 55 & 60 & 55 & 60 \\
\hline & Sense of humor & 64 & 85 & 53 & 74 \\
\hline \multirow[t]{3}{*}{2} & Attractiveness & 86 & 64 & 86 & 64 \\
\hline & Honesty & 60 & 65 & 60 & 65 \\
\hline & Dependability & 65 & 87 & 54 & 76 \\
\hline \multirow{3}{*}{3} & Attractiveness & 84 & 63 & 84 & 63 \\
\hline & Honesty & 60 & 65 & 60 & 65 \\
\hline & Intelligence & 60 & 80 & 50 & 70 \\
\hline \multirow[t]{3}{*}{4} & Attractiveness & 72 & 54 & 72 & 54 \\
\hline & Sense of humor & 54 & 59 & 54 & 59 \\
\hline & Dependability & 69 & 91 & 57 & 80 \\
\hline \multirow{3}{*}{5} & Attractiveness & 80 & 60 & 80 & 60 \\
\hline & Sense of humor & 56 & 61 & 56 & 61 \\
\hline & Intelligence & 61 & 82 & 51 & 72 \\
\hline \multirow{3}{*}{6} & Attractiveness & 81 & 61 & 81 & 61 \\
\hline & Dependability & 51 & 56 & 51 & 56 \\
\hline & Intelligence & 65 & 87 & 54 & 76 \\
\hline \multirow{3}{*}{7} & Honestv & 84 & 63 & 84 & 63 \\
\hline & Sense of humor & 59 & 64 & 59 & 64 \\
\hline & Dependability & 54 & 72 & 45 & 63 \\
\hline \multirow[t]{3}{*}{8} & Honestv & 70 & 53 & 70 & 53 \\
\hline & Sense of humor & 56 & 61 & 56 & 61 \\
\hline & Intelligence & 64 & 85 & 53 & 74 \\
\hline \multirow[t]{3}{*}{9} & Honesty & 72 & 54 & 72 & 54 \\
\hline & Dependability & 56 & 61 & 56 & 61 \\
\hline & Intelligence & 62 & 83 & 52 & 73 \\
\hline \multirow[t]{3}{*}{10} & Sense of humor & 73 & 55 & 73 & 55 \\
\hline & Dependability & 53 & 58 & 53 & 58 \\
\hline & Intelligence & 68 & 90 & 57 & 79 \\
\hline
\end{tabular}

Note. The attribute that we used to manipulate the dominance relation appears in bold.

consider the case in which a prospective dating partner is described as $65 \%$ on physical attractiveness. The percentage point means that this person is more good-looking than $65 \%$ of those UNC (DU) students who are of the same gender, race, and age as the prospective partner.

Participants read through two more examples. Next, participants selected a dating partner in each of the 10 stimulus sets? At the end, participants responded to demographic questions regarding their marital

2. Participants also rated the desirability of each of the prospective dating partners. The results were identical to the reported partner choice results. 
TABLE 3. Percentage of Participants Who Selected Eligible A in Experiment 1

\begin{tabular}{cccc} 
Set & P(A I B $)$ & P(A I BCa) & P(A I BCb) \\
\hline 1 & 25.00 & 42.50 & 25.00 \\
2 & 40.00 & 47.50 & 20.00 \\
3 & 37.50 & 55.00 & 27.50 \\
4 & 37.50 & 57.50 & 20.00 \\
5 & 57.50 & 57.50 & 32.50 \\
6 & 52.50 & 62.50 & 25.50 \\
7 & 67.50 & 67.50 & 40.00 \\
8 & 65.00 & 80.00 & 50.00 \\
9 & 62.50 & 77.50 & 47.50 \\
10 & 55.00 & 67.50 & 45.00 \\
Mean & 50.00 & 61.50 & 33.25 \\
\hline
\end{tabular}

status, ethnicity, gender, age, and relational involvement.$^{3}$ Finally, participants were debriefed and thanked.

\section{RESULTS}

The Field of Eligibles main effect was significant, $F(2,117)=15.90, p<.0001$ (Table 3). Prediction 1 was supported: Participants were more likely to select as a dating partner eligible A when eligible $\mathrm{Ca}$ was present $(M=61.50)$ than when eligible $\mathrm{Ca}$ was absent $(M=50.00), \mathrm{F}(1,117)=5.21, \mathrm{p}<.024$. Prediction 2 was also supported: Participants were less likely to select eligible $A$ as a dating partner when eligible $\mathrm{Cb}$ was present $(M=33.25)$ than when eligible $\mathrm{Cb}$ was absent $(M=$ $50.00), \mathrm{F}(1,117)=5.61, \mathrm{p}<.001$. Likewise, Prediction 3 was supported: Participants were more likely to select as a dating partner eligible $\mathrm{A}$ when eligible $\mathrm{Ca}$ was present $(M=61.50)$ than when eligible $\mathrm{Cb}$ was present $(M=33.25), \mathrm{F}(1,117)=$ $31.44, \mathrm{p}<.0001$.

We further examined the impact of the field of eligibles on partner se-lection by calculating three effect sizes (Table 4). First, we subtracted for each set the baseline condition mean from the decoy-for-eligible-A-present condition mean [i.e., P(A I BCa) - P(A I B)]. According to Prediction 1, the outcome of these subtractions should be positive. This was indeed the case in eight out of 10 stimulus sets. Second, for each set we subtracted the decoy-for-eligible-B-present condition mean from the baseline condition mean [i.e., P(A I B) - P(A I BCb)]. According to Prediction 2, the outcome should be positive. Indeed, the prediction was confirmed in nine out of 10 sets. Finally, we subtracted 
TABLE 4. Effect Sizes in Experiment 1

\begin{tabular}{|lccc}
\hline Set & P(A I BCa) - P(A I B) & P(A I B) - P(A I BCb) & P(A I BCa) - P(A I BCb) \\
\hline 1 & 17.50 & 0.00 & 17.50 \\
2 & 7.50 & 20.00 & 27.50 \\
3 & 17.50 & 10.00 & 27.50 \\
4 & 20.00 & 17.50 & 37.50 \\
5 & 0.00 & 25.00 & 25.00 \\
6 & 10.00 & 27.50 & 37.50 \\
7 & 0.00 & 27.50 & 27.50 \\
8 & 15.00 & 15.00 & 30.00 \\
9 & 15.00 & 15.00 & 30.00 \\
10 & 12.50 & 10.00 & 22.50 \\
Mean & 11.50 & 16.75 & 28.25 \\
\hline
\end{tabular}

the decoy-for-eligible-B-present condition mean from the decoy-for-eligible-Apresent condition mean [i.e., $\mathrm{P}(\mathrm{A}$ I BCa) - $\mathrm{P}(\mathrm{A} \mathrm{I} \mathrm{BCb})$ ]. According to Prediction 3, the outcome should be positive, and this was the case in all 10 sets.

The Replication Set main effect was significant, $F(9,1053)=8.62, p<.0001$. A visual inspection of the results (Tables 3 and 4) indicates that partner selection pertaining to stimulus sets $1-6$ followed a different pattern than partner selection pertaining to sets 7-10. This differential pattern was validated by a statistical comparison between the two stimulus set groupings (i.e., 1-6 vs. 7-10), $\mathrm{F}(1,1053)=$ $60.27, \mathrm{p}<.0001$. We further explored the Replication Set main effect by contrasting the two stimulus set groupings separately on each of the three conditions of the Field of Eligibles factor. In the $\mathrm{AB}$ condition, participants expressed a higher preference for Eligible $A$ in sets 7-10 than in sets $1-6, F(1,351)=$ $20.91, p<.001$. Likewise, participants expressed a higher preference for Eligible A in the $\mathrm{ABCa}$ condition $(\mathrm{F}[1,351]=20.08, \mathrm{p}<.0001)$ and in the $\mathrm{ABCb}$ condition $(\mathrm{F}[1,351]=19.38, \mathrm{p}<.0001)$. Indeed, the overall Field of Eligibles X Replication Set interaction was not sig nificant, $\mathrm{F}(18,1053)=.56, \mathrm{p}<.93$. These rather unexpected results revealed that participants did not regard attractiveness as the most important attribute in a dating partner. These results will have important implications for Experiment 2.

\section{DISCUSSION}

Experiment 1 obtained support for the role of context in partner selection.

Participants manifested the asymmetric dominance effect. For ex- 
ample, they solidified their dating selection of a given eligible (A) over another (B), following the introduction into the field of a third eligible $(\mathrm{Ca})$, who was almost but not quite as appealing as A.

This sort of contextual influence is not predicted by existing social psychological theories. Nonetheless, of all theories, interdependence theory comes closest to being applicable to the issue. This theory, via the concept of CL-alt, addresses the role of context in partner selection. CL-alt refers, in part, to the desirability of alternatives. A given alternative will be preferred to the extent that the benefit-cost balance exceeds that of other alternatives. However, CL-alt does not specify the role of weak alternatives in determining whether a given alternative will be more desir able (i.e., will be perceived as having a higher benefit-cost ratio) than another alternative. Experiment 1 showed that the desirability of a given alternative over a second alternative depends on the contextual configuration of the field of eligibles and, more concretely, on the presence or absence of a third alternative that has an asymmetric dominance relation with one of the alternatives.

Additionally, Experiment 1 found that participants did not consider physical attractiveness as the most important attribute in a prospective dating partner (stimulus sets 1-6). Perhaps the disproportionate presence of women in the sample accounts for this finding (Buss, 1989; Sadalla et al., 1987). Instead, participants placed greater importance on the attributes of honesty and sense of humor than on attractiveness (stimulus sets 7-10). These patterns have implications for the predictions of Experiment 2.

\section{EXPERIMENT 2: PROMINENCE AND PARTNER SELECTION}

The objective of Experiment 2 was to demonstrate the relevancy of the prominence effect to initial partner selection. Participants were presented with two alternatives, eligible A (still the targeted alternative) and eligible B. These hypothetical eligibles were described using the same stimulus sets as in Experiment 1. Participants expressed their preferences for A in terms of either choice or matching. In line with the prominence effect, we predicted the following pattern of preference reversal. Participants will be more likely to select A when this eligible is superior to B on the most important attribute (e.g., honesty) in choice rather than in matching. This pattern was expected in sets 7-10. Additionally, participants will be less likely to select $\mathrm{A}$ when this eligible is superior to $\mathrm{B}$ on the least important attribute (e.g., physical attractiveness) in choice rather than in matching. This pattern was expected in sets 1-6. 


\section{METHOD}

\section{PARTICIPANTS, EXPERIMENTAL DESIGN, AND STIMULUS MATERIALS}

Participants were 294 UNC-CH introductory psychology students fulfilling a course option. Most of the participants were single (98\%), and about half (49\%) were in a dating relationship. The average participant age was 19 years. Also, of the 238 participants who designated their gender, $91 \%$ were females. We assigned participants randomly to the experimental conditions.

The experimental design was balanced and consisted of two factors. The first factor, Selection Mode, was between-participants and had two levels: choice and matching. The second factor, Replication Set, had 10 levels. Each participant received a different random order of the stimulus sets. Correspondingly with Experiment 1, Replication Set was crossed with Selection mode, and participants were a nested variable. We used the exact same stimulus sets, attributes, and attribute percent-ages for Eligible A and Eligible B as in Experiment 1. (See the first two columns of Table 2.)

\section{PROCEDURE}

All stimulus materials were in the same booklet. Instructions appeared on the cover page of the booklet. Participants in the choice condition were told that they would be provided with information about two eligibles, $\mathrm{A}$ and $\mathrm{B}$, and would be asked to select one as a dating partner. Participants in the matching condition were informed that the purpose of the study was to understand what makes prospective partners equally appealing. As an example, they were asked to imagine that Eligible A is an 80 on intelligence, but is a 50 on attractiveness (with 100 being the highest possible rating). Eligible $\mathrm{B}$, on the other hand, is a 60 on intelligence. What score should $\mathrm{B}$ receive on attractiveness in order for this person to be as appealing to the participant as A? Participants in both the choice and matching conditions were further informed that they would be presented with several hypothetical eligibles, and were invited to assume that these eligibles were UNC students of approximately the same age as they were. Next, all participants read through three examples, as in Experiment 1, and completed either the choice or the matching response task. Participants in the choice condition responded to the question "I choose Eligible _ (A or B)." Participants in the matching condition responded to the question "What percentage does Eligible A need to be on (first attribute of each set) in order for Eligible A to be as 


\begin{tabular}{cccccc}
\multicolumn{6}{c}{ TABLE } \\
\hline $\begin{array}{r}\text { Se } \\
\mathrm{t}\end{array}$ & $\begin{array}{c}\text { Choice } \\
\text { Condition }\end{array}$ & $\begin{array}{c}\text { Matching } \\
\text { Condition }\end{array}$ & Difference & $\begin{array}{c}\mathrm{t}- \\
\text { test }\end{array}$ & p level \\
\hline 1 & 25.17 & 64.63 & -39.46 & -7.38 & .0001 \\
2 & 27.21 & 76.19 & -48.98 & -9.67 & .0001 \\
3 & 34.69 & 74.15 & -39.46 & -7.37 & .0001 \\
4 & 50.34 & 49.66 & .68 & .12 & .91 \\
5 & 39.46 & 75.51 & -36.05 & -6.69 & .0001 \\
6 & 48.98 & 72.79 & -23.81 & -4.29 & .0001 \\
7 & 65.31 & 67.35 & -2.04 & -.37 & .71 \\
8 & 85.03 & 46.94 & 38.09 & 7.50 & .0001 \\
9 & 83.67 & 47.62 & 36.05 & 7.01 & .0001 \\
10 & 71.43 & 39.46 & 31.97 & 5.81 & .0001 \\
Mean & 53.13 & 61.42 & -8.29 & &
\end{tabular}

appealing to you as eligible B?" At the end participants responded to demographic questions regarding their marital status, gender, age, and relational involvement; ${ }^{4}$ then they were debriefed and thanked.

\section{RESULTS}

The Selection Mode main effect was significant. Participants preferred Eligible A to a greater extent in the matching $(M=61.42)$ than in the choice $(M=53.13)$ condition, $\mathrm{F}(1,292)=8.05, p<.005$. The Replication Set main effect was also significant, $F(9,2628)=9.57, p<.0001$. Of critical importance, however, was the significant interaction, $F(9,2628)=51.15, p<.0001$ (Table 5).

We predicted that participants would be more likely to select Eligible

A when this eligible was superior to eligible B on the most important at-tribute (e.g., honesty) in choice rather than in matching. This pattern was expected in sets 7-10. The prediction was confirmed. Participants ex-pressed a higher preference for A $(M$ $=76.35)$ in choice than in matching mode $(M=50.33), \mathrm{F}(1,876)=56.22, p<.0001$. (This pattern was obtained in three out of four stimulus sets.) Furthermore, we predicted that participants would be less likely to select A when this eligible was superior to

$\mathrm{B}$ on the least important attribute (e.g., physical attractiveness) in choice rather than in matching mode. This pattern was expected in sets $1-6$. This prediction was also corroborated. Participants were less likely to prefer A $(M=37.65)$ in choice than in matching $(M=68.82), \mathrm{F}(1,1460)=81.93, p<.0001$. (This pattern was obtained in five out of six stimulus sets.) 


\section{DISCUSSION}

Experiment 2 demonstrated procedural influences on partner selection. Participants manifested the prominence effect. Which eligible was selected as a dating partner depended upon (1) how the selection mode was carried out, (2) the relative importance to the participant of an eligible's attribute, and (3) the relative standing of the eligibles on the attribute important to the participant. Specifically, participants were more likely to select in choice than in matching the eligible superior on an at-tribute important to the participants. On the other hand, participants were more likely to select in matching than in choice the eligible superior on an attribute less important to the participants.

This sort of procedural influence on partner selection is not predicted by extant theoretical accounts. Nevertheless, as in Experiment 1, the applicability of interdependence theory needs to be considered. This the ory proposes the concept of CL, which refers to relationship expectancies. On the face of it, CL does not appear relevant, given that Experiment 2 kept relationship expectancies constant. On the other hand, one legacy of interdependence theory is built upon a distinction between attraction and choice. This theory assumes that partners (or other outcomes) are projected onto a single scale in terms of which they are evaluated for attractiveness by reference to the CL. In making a choice, the individual narrows the range to the two most attractive alternatives. With the narrowing of the range, all other alternatives and the CL become irrelevant, as only two alternatives are engaged. Still, however, interdependence theory does not offer predictions regarding the prevalence of the choice versus the matching response task as a function of the importance of partner attribute.

Relatedly, we wish to state an untested assumption we have made. We assumed that choice and matching are decision tasks that take place con-currently. Stated otherwise, we assumed that an individual will select a partner in accord with his or her matches. However, matching and choice may take place at different points in time and may not correspond directly. In fact, it is reasonable to hypothesize that matching affects the $\mathrm{CL}$, whereas choice does not. This is a hypothesis worth testing in future research.

\section{GENERAL DISCUSSION}

The problem of partner selection has been a classic topic of inquiry in the social psychological literature. Several determinants of partner selection have been proposed such as evolutionary- and need-based predilections, reward contingencies, interdependence processes, attachment 
present investigation complements past research by viewing partner se-lection as an on-line, dynamic, and often tentative decision-making pro-cess. As such, partner selection will be affected by the contextual configuration of the field of eligibles (i.e., presence or absence of a seemingly irrelevant alternative) and by the mode through which the selection process is carried out.

\section{THE ASYMMETRIC DOMINANCE EFFECT: SUMMARY OF FINDINGS AND EXPLANATIONS}

We focused first on the contextual determinant of asymmetric dominance. According to this effect, introduction in a two-person field of eligibles of a third eligible (e.g., Ca) dominated by the first eligible (A) but not by the second one (B) will tip the scale toward selecting the first eligible. Experiment 1 indeed established the influence of asymmetric dominance on partner selection. We should note that this contextually determined partner-selection strategy violates normative and rational models of decision making, which assume that the introduction of a new person in the field of eligibles will decrease one's preference for all eligibles, and, particularly, for the other most similar eligible. That is, such models (e.g., Luce, 1959; Tversky, 1972) predicted that the intro-duction of Eligible Ca would, if anything, make the selection of Eligible A less likely because of the high degree of similarity between $\mathrm{Ca}$ and $\mathrm{A}$.

Three theoretical explanations for the asymmetric dominance effect have been offered (Wedell, 1991). One explanation, the weight-change model, proposes that the addition of a decoy changes the relative weights that participants assign to the attributes of the other alternatives. The change in relative weights renders the targeted alternative (i.e., Eligible A) more desirable. The second explanation, the value-shift model (Ariely \& Wallsten, 1995; Mellers \& Cooke, 1994), assumes that the addition of the decoy changes not the weights (which remain constant) but rather the subjective values that participants as-sign to the alternatives. As a result, the desirability of the targeted alternative is increased. Finally, the third explanation, the value-added model (Simonson, 1989), generally proposes that the increase in the desirability of the targeted alternative is due to an increase in its justifiability. Wedell and Pettibone (1996) have evaluated these three explanations and obtained support for the latter two. Future research may need to reevaluate these explanations in the domain of dating partner selection. 


\section{THE PROMINENCE EFFECT: SUMMARY OF FINDINGS AND EXPLANATIONS}

We also focused on procedural determinants of partner selection and, more specifically, on the prominence effect. According to this effect, participants will assign (1) more weight to important attributes when evalu ating eligibles in choice rather matching response tasks, and (2) more weight to unimportant attributes when evaluating eligibles in matching than in choice response tasks. Indeed, Experiment 2 demonstrated that eligible A was selected in the first case, whereas eligible B was selected in the second case. This procedurally determined partner-selection strategy violates an assumption central to normative and rational decision-making models, namely the assumption of procedural invariance. Such models assume that the outcome of partner selection will be invariant across selection modes. Equivalent procedures should lead to equivalent outcomes.

One explanation for the prominence effect is the compatibility hypothesis (Tversky et al., 1988; see also Fischer \& Hawkins, 1993). Choice re-quires a qualitative (i.e., ordering) response. Qualitative responses are naturally compatible with qualitative decision making processes, which lead individuals to prefer alternatives superior on the most important attribute. On the other hand, matching requires a quantitative response, which is naturally compatible with quantitative decision-making processes. Such processes lead individuals to substitute one attribute for an-other (i.e., to engage in trade-offs), thus assigning some weight to all attributes. Another explanation for the prominence effect is the task goal hypothesis (Fischer, Carmon, Ariely, \& Zauberman, 1998). The most important attribute is weighted more heavily in tasks where the goal is to differentiate among alternatives (choice) rather than in tasks where the goal is to equate the alternatives (matching). Future research should explore in more detail the mechanisms underlying the presence of the prominence effect in the domain of dating partner selection.

\section{ISSUES OF GENERALIZABILITY}

To what extent are the findings of the present research generalizable? We wish to discuss four generalizability caveats.

First, we described the eligibles in terms of three attributes. Certainly, more than three attributes are typically needed for an individual to form a coherent impression of another person (Ostrom, 1975). Nevertheless, there is reason to belie ve that the present findings would be generalizable to a substantially higher number of attributes. Indeed, 
asymmetric dominance and prominence effects have been obtained with more than five attributes (Ariely \& Sedikides, 1999).

Second, not only the number, but also the kind of attributes used is un-likely to alter the pattern of our findings. For example, physical attractiveness was not regarded by the participants as a particularly important partner attribute. However, the importance of a specific attribute was not critical to the objectives and findings of Experiment 1. The asymmetric dominance effect is based on shifts in relative preferences as a function of decoy introduction rather than on the absolute magnitude of participants' a priori preferences. The same point is relevant to the prominence effect.

Third, we assumed that partner selection is based on direct decisions by the individuals involved. Although this is generally the case in West-ern culture, for much of Eastern culture (and, indeed, for much of history in both Western and Eastern culture) direct selection on the part of the two individuals is the exception rather than the rule. We believe, though, that this observation qualifies the generalizability of our findings in only a limited way: Contextual and procedural influences are still likely to color the partner selection decisions that family or community members make on behalf of the individual.

Finally, our experimental procedures apply best in cases in which initial partner preferences are formed through "lonely heart" advertisements, partner descriptions obtained from friends, reflection on recent acquaintances, or responses to questions that friends or relatives pose (in the form of choice or matching) about desirability of eligibles. Arguably, our procedures have limited applicability in a socially interactive setting. Admittedly, partner selection is a controversial area for testing any kind of decision theory, because partner selection is subject to negotiation between the two individuals involved ${ }^{5}$ No matter how much Homer wants to hook up with the fair Ophelia, if she will not have him, she will not be his partner. Indeed, a major strength of interdependence theory is the specification of patterns of giveand-take as two prospective partners attempt to gauge the benefits and costs of a relationship (Rusbult \& Arriaga, 1997). Nevertheless, for the negotiation of wills and desires to ensue, an initial approach of the prospective partner is necessary. We believe that this approach lends itself to decision-making influences such as the asymmetric dominance and prominence effects.

5. Abandoning a relationship may be a more appropriate domain for applying decision theory to relational processes. If an individual is prepared to pay a high enough price (operationalized in terms of a matching response task) for abandoning a relationship, the individual has the potential to do so. In fact, the price the individual is willing to pay would

constitute an informative denendent measure. 


\section{CONCLUDING REMARKS}

We do not wish to be construed as arguing that early-stage partner selection is random. Instead, we argue that early-stage partner selection can be imperfect or nonrational (i.e., amenable to contextual and procedural influences). However, a non-rational partner selection strategy can have long-term repercussions. Individuals may end up dating the person they singled out, and, if so, they will become familiar with this person; in turn, this familiarity may breed liking (Saegert, Swap, \& Zajonc, 1973). Commitment processes (Rusbult, 1980) may emerge. Relational bonds will be established that may lead to marital partnership. It is because of these possible and serious long-term relationship consequences that we opted to illustrate in this article some contextual and procedural determinants of partner selection.

\section{REFERENCES}

Ariely, D., \& Sedikides, C. (1999). The asymmetric dominance effect: Judgments of esthetics. Unpublished data, Massachussetts Institute of Technology, Sloan School of Business.

Ariely, D., \& Wallsten, T. S. (1995). Seeking subjective dominance in multidimensional space: An explanation of the asymmetric dominance effect. Organizational Behavior and Human Decision Processes, 63, 223-232.

Aron, A., \& Aron, E. N. (1997). Self-expansion motivation and including other in the self. In S. Duck (Ed.), Handbook of personal relationships: Theory, research and intervention (2nd ed., pp. 251-270). Chichester: Wiley.

Aron, A. P., Dutton, D. G., Aron, E. N., \& Iverson, A. (1989). Experiences of falling in love. Journal of Social and Personal Relationships, 6, 243-257.

Baumeister, R. F., \& Leary, M. R. (1995). The need to belong: desire for interpersonal attachments as a fundamental human motivation. Psychological Bulletin, 117, 497-529.

Buss, D. M. (1989). Sex differences in human mate preferences: Evolutionary hypotheses tested in 37 cultures. Behavioral and Brain Sciences, 12, 1-49.

Byrne, D. (1971). The attraction paradigm. New York: Academic Press.

Chappell, K. D., \& Davis, K. E. (1998). Attachment, partner choice, and perception of romantic partners: An experimental test of the attachment -security hypothesis. Personal Relationships, 5, 327-342.

Dutton, D. G., \& Aron, A. P. (1974). Some evidence for heightened sexual attraction under conditions of high anxiety. Journal of Personality and Social Psychology, 30, 510-517.

Fischer, G. W., Carmon, Z., Ariely, D., \& Zauberman, G. (1998). Goatbased construction of preferences: Task goals and the prominence effect. Manuscript under review. Fuqua School of Business, Duke University.

Fischer, G. W., \& Hawkins, S. A. (1993). Strategy, compatibility, scale compatibility, and the prominence effect. Journal of Experimental Psychology: Human Perception and Perfarmance, 19, 580597.

Frazier, P., Byer A. L., Fischer, A. R., Wright, D. M., \& DeBord, K. A. (1996). Adult attachment style and partner choice: correlational and experimental findings. Personal Relationships, 3, 117-136.

Hazan, C., \& Shaver, P. R. (1994). Attachment as an organizational framework for research on close relationships. Psychological Inquiry, 5,1-22. 
Hinsz, V. B. (1989). Facial resemblance in engaged and married couples. Journal of Social and Personal Relationships, 6, 223-229.

Huber, J., Payne, J. W., \& Puto, C. (1982). Adding asymmetrically dominated alternatives: Violations of regularity and the similarity hypothesis. Journal of Consumer Research, 9, 90-98.

Huber, J., \& Puto, C. (1983). Market boundaries and product choice: Illustrating attraction and substitution effects. Journal of Consumer Research, 10,31-44.

Kelley, H. H., \& Thibaut, J. W. (1978). Interpersonal relations: A theory of interdependence. New Y ork: Wiley.

Lott, A. J., \& Lott, B. A. (1974). The role of reward in the formation of positive interpersonal attitudes. In T. Huston (Ed.), Foundations of interpersonal attraction (pp. 171-189). New Y ork: Academic Press.

Luce, it D . (1959). Individual choice behavior. New Y ork: Wiley.

Mellers, B. A., \& Cooke, A. D . J. (1994). Trade-offs depend on attribute range. Journal of Experimental Psychology: Human Perception and Performance, 20, 1055-1067.

Newcomb, T. M. (1961). The acquaintance process. New Y ork: Holt, Rinehart \& Winston. O strom, T. M. (1975). Cognitive representation of impressions. Paper presented at the meeting of the American Psychological Association, Chicago, August 1975.

Payne, J. W., Bettman, J. R., \& Johnson, E. J. (1993). The adaptive decision maker. New York: Cambridge University Press.

Pietromonaco, P. it, \& Carnelley, K. B. (1994). Gender and working models of attachment: Consequences for perceptions of self and romantic relationships. Personal Relation-ships, 1, 63-82.

Reis, H. T., \& Shaver, P. (1988). Intimacy as an interpersonal process. In S. Duck (Ed.), Handbook of personal relationships: Theory, research, and interventions (1st ed., pp. 367-389). Chichester: Wiley.

Rusbult, C. E. (1980). Commitment and satisfaction in romantic associations: A test of the investment model. Journal of Experimental Social Psychology, 16,172-186.

Rusbult, C. E., \& Arriaga, X. B. (1997). Interdependence theory. In S. Duck (Ed.), Handbook of personal relationships: Theory, research, and interventions (2nd ed., pp. 221-250). Chichester: Wiley.

Sadalla, E. K., Kenrick, D. T., \& Vershure, B. (1987). D ominance and heterosexual attraction. Journal of Personality and Social Psychology, 52, 730-738.

Saegert, S. C., Swap, W., \& Zajonc, R. (1973). Exposure, context, and interpersonal attraction. Journal of Personality and Social Psychology, 25,234-242.

Sedikides, C., Oliver, M. B., \& Campbell, W. K. (1994). Perceived benefits and costs of romantic relationships for women and men: Implications for exchange theory. Personal Relationships, 1, 521.

Simonson, I. (1989). Choice based on reasons: The case of attraction and compromise effects. Journal of Consumer Research, 16, 158-174.

Slovic, P. (1975). Choice between equally valued alternatives. Journal of Experimental Psychology: Human Perception and Performance, 1, 280-287.

Tharp, R. G. (1963). Psychological patterning in marriage. Psychological Bulletin, 60, 97-117.

Thibaut, J. W., \& Kelley, H. H. (1959). The social psychology of groups. New York: Wiley. Tversky, A. (1972). Elimination by aspects: A theory of choice. Psychological Review, 79, 281-299.

Tversky, A., Sattath, S., \& Slovic, P. (1988). Contingent weighting in judgment and choice. Psychological Review, 95, 371-384.

Wedell, D. H. (1991). Distinguishing among models of contextually induced preference reversals. Journal of Experimental Psychology: Learning, Memory, and Cognition, 17, 767-778. 
Wedell, D. H., \& Pettibone, J. C. (1996). Using judgments to understand decoy effects in choice. Organizational Behavior and Human Decision Processes, 67,326-344.

Wetzel, C. G., \& Insko, C. A. (1982). The similarity-attraction relationship: Is there an ideal one? Journal of Experimental Social Psychology, 18, 253-276. 